\title{
Is There Any Relationship between Maternal Vitamin D Levels and Asymptomatic Bacteriuria? A Preliminary Study
}

\author{
Emel Kurtoglu Ozdes ${ }^{1}$, Bahattin Avci ${ }^{2}$, Samettin Celik ${ }^{3}$, Gokhan 0cal ${ }^{4}$, Serap Polat ${ }^{5}$, \\ Feyza Munevver Yaran', Taskin Ozdes ${ }^{7}$, Migraci Tosun ${ }^{8}$, Arif Kokcu ${ }^{9}$ \\ ${ }^{1}$ Department of Obstetrics and Gynecology, Memorial Hizmet Hospital, Istanbul, Turkey \\ ${ }^{2}$ Department of Biochemistry, Faculty of Medicine, Ondokuz Mayis University, Samsun, Turkey \\ ${ }^{3}$ Maternity Hospital, Samsun Training and Research Hospital, Samsun, Turkey \\ ${ }^{4}$ Department of Obstetrics and Gynecology, Buyuk Anadolu Hospital, Samsun, Turkey \\ ${ }^{5}$ Department of Obstetrics and Gynecology, Private Meditech Hospital, Ordu, Turkey \\ ${ }^{6}$ Obstetrics and Gynecology, Independent researcher, Istanbul, Turkey \\ ${ }^{7}$ Forensic Medicine, Independent researcher, Istanbul, Turkey \\ ${ }^{8}$ Department of Obstetrics and Gynecology, Faculty of Medicine, Ondokuz Mayis University, Samsun, Turkey \\ ${ }^{9}$ Department of Obstetrics and Gynecology, Medical Park Samsun Hospital, Samsun, Turkey \\ Email: ^emel0022@mynet.com
}

How to cite this paper: Ozdes, E.K., Avci, B., Celik, S., Ocal, G., Polat, S., Yaran, F.M., Ozdes, T., Tosun, M. and Kokcu, A. (2020) Is There Any Relationship between Maternal Vitamin D Levels and Asymptomatic Bacteriuria? A Preliminary Study. Open Journal of Obstetrics and Gynecology, 10, 1677-1685. https://doi.org/10.4236/ojog.2020.10120151

Received: September 1, 2020

Accepted: December 11, 2020

Published: December 14, 2020

Copyright $\odot 2020$ by author(s) and Scientific Research Publishing Inc. This work is licensed under the Creative Commons Attribution International License (CC BY 4.0).

http://creativecommons.org/licenses/by/4.0/

(c) (i) Open Access

\begin{abstract}
Hypothesis: Vitamin D has been considered to play important roles in maintaining pregnancy. Also, this vitamin is considered to regulate immune response and thus may be important for pregnant women also to maintain no-infection of which preterm delivery is especially important. Since vitamin $\mathrm{D}$ regulates maternal anti-infection function and since Asymptomatic bacteriuria (ASB) causes various adverse outcomes in pregnancy, we hypothesized that maternal serum vitamin $\mathrm{D}$ level may be related with the presence/absence of ASB. The present study was an effort to determine this. The study included 215 pregnant women, attended the Ondokuz Mayis University Hospital antenatal care polyclinic, Samsun, Turkey, in the summer for initial visits between 6- and 14-weeks' gestation. Women with symptoms suggestive of urinary tract infection, a history of antibiotic use within the previous two weeks, ongoing antibiotic therapy or urinary system instrumentation, a diagnosis of vitamin $\mathrm{D}$ insufficiency or deficiency, and those taking vitamin D supplements were excluded. Demographic data features of the sampled women were analyzed retrospectively. $10 \mathrm{ml}$ maternal peripheral venous blood samples were collected and the concentrations of $25(\mathrm{OH}) \mathrm{D}_{3}$ in the serum were analyzed. Mid-stream morning urine samples were obtained and analyzed at the microbiology laboratory according to established proce-
\end{abstract}


dures. ASB was reported if bacteria were present at specified quantitative counts $\left(\geq 10^{5} \mathrm{CFU} / \mathrm{ml}\right)$ in the urine without any sign or symptom. Participants were divided into two groups: ASB $(-)$-participants without ASB $(\mathrm{n}=200)$ and: ASB $(+)-$ participants with ASB $(n=15)$. There was no statistically significant relationship between the two groups in terms of demographic features. There was no statistically significant relationship between the distribution of maternal $25(\mathrm{OH}) \mathrm{D}_{3}$ levels in the two groups $(\mathrm{p}>0.05)$. The comparison of maternal median $25(\mathrm{OH}) \mathrm{D}_{3}$ levels between the two groups showed no statistically significant difference $(\mathrm{p}=0.576)$. No statistically significant correlation was found between $25(\mathrm{OH}) \mathrm{D}_{3}$ levels and age, gravida, parity, body weight, or gestation week $(p>0.05)$. Although there was no significant relationship between maternal vitamin D levels and ASB in this research, further studies in larger groups will increasingly highlight and clarify this topic.

\section{Keywords}

Pregnancy, Asymptomatic Bacteriuria, Vitamin D, Perinatal Complication, Supplementation

\section{Introduction}

Asymptomatic bacteriuria (ASB) - which has a prevalence of approximately $1.9 \%-9.5 \%$ during pregnancy and is defined as the presence of bacteria at specified quantitative counts $\left(\geq 10^{5}\right.$ colony-forming units $\left.[\mathrm{CFU}] / \mathrm{ml}\right)$ in the urine without any sign or symptom-is particularly important in perinatal complications, such as preterm labor, anemia, prematurity, pyelonephritis, hypertensive disorder, intrauterine growth restriction, preterm premature rupture of membrane, and low birth weight [1]. Therefore, the Infectious Diseases Society of America (IDSA) and the US Preventive Service Task Force (USPSTF) recommend screening for ASB via a urine culture at least once during the first prenatal visit (ideally before 16-weeks' gestation) and treating it with appropriate antibiotics to prevent serious complications [2].

In addition to screening and treatment, preventive measures against ASB, such as balanced nutrition in terms of required macro- and micronutrients, are also crucial. Vitamin D, which is one of the most important micronutrients for human life and pregnancy, has been reported to have a global deficiency of $29.8 \%$ and insufficiency of $87.0 \%$ [3] [4]. In contrast to previous beliefs, it has been suggested that vitamin $\mathrm{D}$ is not only required for calcium homeostasis but that it also plays a significant role in the immune system, in glucose metabolism, in the regulation of cell proliferation and differentiation, and in fetal growth during pregnancy [5]. Recently, there has been incredible interest in vitamin D during pregnancy, and, as a result, researchers have found a significant relationship between low maternal vitamin $\mathrm{D}$ levels and adverse maternal-fetal outcomes, including gestational diabetes mellitus (GDM), preeclampsia, preterm 
labor, and babies being born small for gestational age (SGA) [6] [7].

However, despite so many investigations focusing on the association between maternal vitamin D levels and pregnancy outcomes, no study has, as yet, evaluated whether there is a relationship between vitamin D levels and ASB in pregnancy. Therefore, the present study aimed to determine, for the first time, a possible association between ASB and maternal vitamin D levels at the initial prenatal visit.

\section{Material and Methods}

This study included 215 pregnant women with low-risk, who lived in the Samsun, Turkey, city center and attended the Ondokuz Mayis University Hospital antenatal care polyclinic in the summer for initial visits between six- and 14-weeks' gestation. Women with symptoms suggestive of UTIs (urgency, frequency, dysuria, suprapubic pain), a history of antibiotic use within the previous two weeks, ongoing antibiotic therapy or urinary system instrumentation, a diagnosis of vitamin D insufficiency or deficiency, and those taking vitamin D supplements were excluded. Informed consent was obtained from all participants.

Demographic data features of the sampled women-including age, gravida, parity, body weight, and gestational age at diagnosis of ASB-were analyzed retrospectively. The study was approved by the Committee for Medical Research Ethics of Ondokuz Mayis University.

During the sampled women's first trimesters (six- to 14-weeks' gestation), 10 $\mathrm{ml}$ of maternal peripheral venous blood samples were collected and centrifuged (Shimadzu UV160A, S.No: 28006648, Japan) at $3000 \mathrm{xg}$ for 10 minutes, and the serums were stored at $-80^{\circ} \mathrm{C}$. On evaluation day, the samples were melted at room temperature. All assays were conducted according to the manufacturer's instructions.

The concentrations of $25(\mathrm{OH}) \mathrm{D}_{3}$ in the serum were analyzed by a Thermo Scientific TSQ Quantum Access Max device using commercially available liquid chromatography/mass spectrophotometry (LC-MS) assay kits (Recipe ClinMass LC-MS/MS, 25(OH) $\mathrm{D}_{3}$, Ref. No. MS7012). The expected values of the test were $20-70 \mathrm{ng} / \mathrm{ml}$. The lower detection limit of the test was $0.67 \mathrm{ng} / \mathrm{ml}$.

Mid-stream morning urine samples were obtained and analyzed at the microbiology laboratory according to established procedures. ASB was reported if bacteria were present at specified quantitative counts $\left(\geq 10^{5} \mathrm{CFU} / \mathrm{ml}\right)$ in the urine without any sign or symptom.

Statistical analyses were carried out using the IBM SPSS Statistics 17.0 (IBM Corporation, Armonk, NY, USA) program. The Kolmogorov-Smirnov test was used to determine whether the distribution of discrete numeric variables was close to a normal distribution. Definitive statistics were identified as discrete numeric variables, mean \pm standard deviation, or median (minimum-maximum); categorical variables were identified as case number and percentage (\%). The statistical significance between groups in terms of the mean value was determined 
using Student's t-test, while the Mann-Whitney U test determined the significance of variables far from normal distribution. Categorical variables were determined by continuity correction chi-squared test or Fisher's probability exact test. Spearman's rank-order correlation test was used to determine whether there was a statistically significant correlation between maternal $25(\mathrm{OH}) \mathrm{D}_{3}$ levels and maternal age, gravida, parity, body weight, and gestation week. A p value $<0.05$ was considered statistically significant.

\section{Results}

The study included 215 pregnant women, and participants were divided into two groups: ASB $(-)$-participants without ASB $(\mathrm{n}=200)$ and ASB $(+)$-participants with ASB $(n=15)$. There was no statistically significant relationship between the two groups in terms of maternal age, gravida, parity, body weight, or gestational weeks ( $p>0.05$ ) (Table 1 )

There was no statistically significant relationship between the distribution of maternal $25(\mathrm{OH}) \mathrm{D}_{3}$ levels in the two groups ( $\left.\mathrm{p}>0.05\right)$ (Table 2) (Figure 1).

The comparison of maternal median $25(\mathrm{OH}) \mathrm{D}_{3}$ levels between the two groups showed no statistically significant difference $(\mathrm{p}=0.576)$.

In the whole study group, no statistically significant correlation was found between $25(\mathrm{OH}) \mathrm{D}_{3}$ levels and age, gravida, parity, body weight, or gestation week $(\mathrm{p}>0.05)$ (Table 3$)$.

Table 1. Demographic features of the study group.

\begin{tabular}{cccc}
\hline & Group 1 (n=200) & Group 2 $(\mathrm{n}=15)$ & p-value \\
\hline Age (year) & $27.9 \pm 6.0$ & $27.3 \pm 6.7$ & $0.734 \dagger$ \\
Gravida & $2(1-6)$ & $3(1-5)$ & $0.120 \ddagger$ \\
Parity & $1(0-4)$ & $1(0-3)$ & $0.192 \ddagger$ \\
Body weight $(\mathrm{kg})$ & $68.8 \pm 13.8$ & $68.8 \pm 10.3$ & $0.997 \dagger$ \\
Gestational week & $17(6-29)$ & $13(5-21)$ & $0.065 \ddagger$ \\
$25(\mathrm{OH}) \mathrm{D}_{3}(\mathrm{ng} / \mathrm{ml})$ & $10.6(0.5-54.7)$ & $11.8(2.3-31.6)$ & $0.576 \ddagger$
\end{tabular}

$\dagger$ Data shown as mean \pm standard deviation, Student's t-test; $\ddagger$ Data explained as median (minimum maximum), Mann-Whitney U test.

Table 2. The distribution of maternal $25(\mathrm{OH}) \mathrm{D}_{3}$ levels between the two groups.

\begin{tabular}{cccc}
\hline & Group 1 $(\mathrm{n}=200)$ & Group 2 $(\mathrm{n}=15)$ & p-value \\
\hline $0-10 \mathrm{ng} / \mathrm{ml}$ & $93(46.5 \%)$ & $6(40.0 \%)$ & $0.827 \dagger$ \\
$10-20 \mathrm{ng} / \mathrm{ml}$ & $57(28.5 \%)$ & $5(33.3 \%)$ & $0.769 \ddagger$ \\
$20-30 \mathrm{ng} / \mathrm{ml}$ & $24(12.0 \%)$ & $3(20.0 \%)$ & $0.411 \ddagger$ \\
$30-40 \mathrm{ng} / \mathrm{ml}$ & $18(9.0 \%)$ & $1(6.7 \%)$ & $>0.999 \ddagger$ \\
$40-60 \mathrm{ng} / \mathrm{ml}$ & $8(4.0 \%)$ & $0(0.0 \%)$ & $>0.999 \ddagger$
\end{tabular}

Data shown as case number and (\%), †continued correction Chi Square test, and $¥$ Fisher’s probability exact test. 


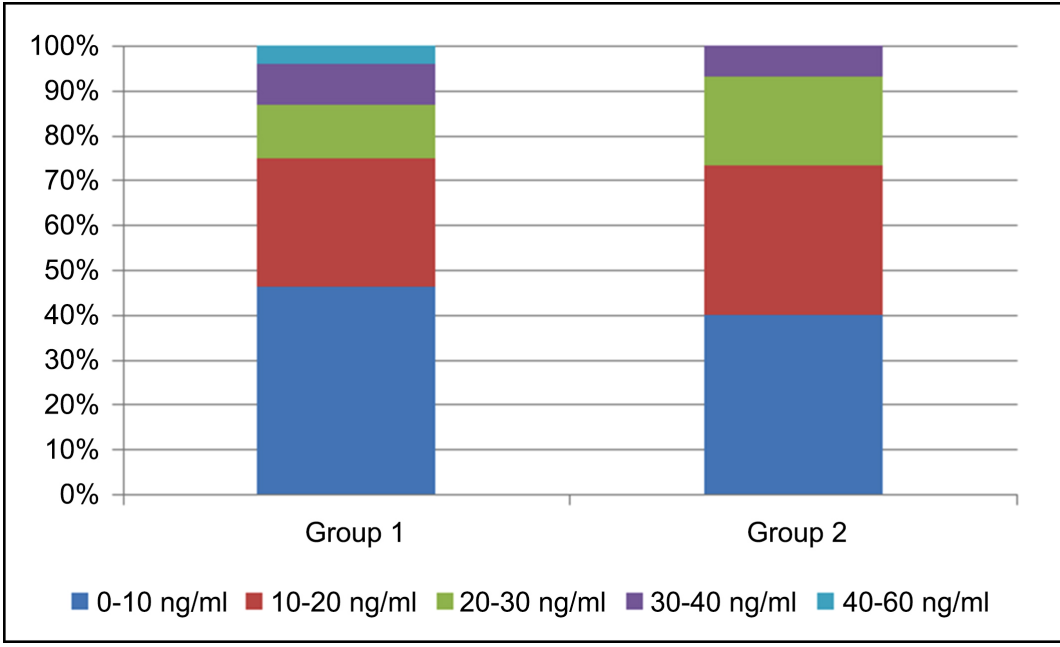

Group 1 Group 2

$0-10 \mathrm{mg} / \mathrm{ml} \quad 46.5 \quad 40$

$10-20 \mathrm{ng} / \mathrm{ml} \quad 28.5 \quad 33.3$

$20-30 \mathrm{ng} / \mathrm{ml} \quad 12 \quad 20$

$30-40 \mathrm{ng} / \mathrm{ml} \quad 9 \quad 6.7$

$40-60 \mathrm{ng} / \mathrm{ml} \quad 4 \quad 0$

Figure 1. The distribution of maternal $25(\mathrm{OH}) \mathrm{D}_{3}$ levels between the two groups.

Table 3. The correlation ratios and significance levels between maternal $25(\mathrm{OH}) \mathrm{D}_{3}$ levels and demographic and clinical features.

\begin{tabular}{cccc}
\hline & $\mathrm{n}$ & Correlation ratio & p-value $\dagger$ \\
\hline Age & 215 & 0.037 & 0.592 \\
Gravida & 215 & -0.081 & 0.240 \\
Parity & 215 & -0.059 & 0.386 \\
Body weight & 215 & 0.003 & 0.960 \\
Gestation week & 215 & 0.069 & 0.316 \\
\hline
\end{tabular}

$\dagger$ Spearman’s rank-order correlation test.

\section{Discussion}

Vitamin D, which is one of the most important micronutrients in pregnancy, can be obtained in several ways: synthesized from 7-dehydrocholesterol in the skin, drawn from exposure to ultraviolet irradiation (UV), or taken in via the diet. It must then be converted into $25(\mathrm{OH}) \mathrm{D}_{3}$ by liver and further changed into its active form, $1.25(\mathrm{OH}) \mathrm{D}_{3}$, in the kidneys, brain, lungs, or placenta. Blood levels of vitamin D are well-known to be affected by several factors-such as maternal age, race, pre-pregnancy body weight, and season of blood sample collection, geographic site, and the vitamin $\mathrm{D}$ receptor gene variants that mediate most biological activities [8] [9] [10]. However, since both mother and fetus can be adversely affected by vitamin D insufficiency, the adequate level of vitamin $\mathrm{D}$ has become one of the most controversial topics in pregnancy. Levels below $20 \mathrm{ng} / \mathrm{ml}$ have been accepted as exhibiting deficiency; levels at $21-29$ $\mathrm{ng} / \mathrm{ml}$ represent insufficiency; and levels above $30 \mathrm{ng} / \mathrm{ml}$ are adequate [11]. In this study, 26 (13\%) pregnant women had adequate vitamin D levels, but only one of them (6.7\%) was in the ASB group. Unfortunately, a huge portion of this sampled group presented vitamin $\mathrm{D}$ insufficiency or deficiency, and there was no significant association between vitamin D level and ASB, as well as no corre- 
lation between vitamin $\mathrm{D}$ and demographic or clinical features.

While the relationship between maternal vitamin $\mathrm{D}$ levels and pregnancy complications, such as GDM, preeclampsia, and SGA has been determined, researchers have also suggested possible related mechanisms, including the effects of vitamin D on immunity, glucose metabolism, fetal development, and calcium homeostasis [12] [13] [14]. However, UTIs, which are one of the most common problems seen in pregnancy due to reduced immunity and anatomical and physiological changes in the urinary tract, have been of little interest in terms of possible relationships with maternal vitamin D levels. Apart from a study conducted in a nursing home, which found a significant relationship between vitamin D levels below $25 \mathrm{nmol} / \mathrm{L}$ and ASB, only one investigation by Hangsdoot et al. has covered this topic [15]. Hangsdoot et al. mention the significant association between maternal vitamin D levels lower than $20 \mathrm{ng} / \mathrm{ml}$ and UTIs. Furthermore, they report serum vitamin D levels of less than $20 \mathrm{ng} / \mathrm{ml}$ as the only factor associated with UTIs after adjusting for all confounders in multiple binary logistic regression modeling and draw attention to the immunoregulatory effect of vitamin D. This effect was first suggested in rachitic children with recurrent respiratory infections. Vitamin D was then used to empirically treat tuberculosis due to the expected effects of UV radiation: killing the causative agent. In line with such research, several in-vitro and in-vivo studies have considered the possible relationship between vitamin $\mathrm{D}$ and severe immune and inflammatory diseases and autoimmune diseases [16] [17]. These experiments have attracted attention to intracellular vitamin D receptors (VDRs), which are present in monocytes/macrophages, $\mathrm{T}$ and $\mathrm{B}$ cells, natural killers, and dendritic cells, and have highlighted the role of vitamin $\mathrm{D}$ in both the innate and acquired immune system. Vitamin D modulates the secretion of antimicrobial peptides-cathelicidine and defensis-which are the initial reactive agents in innate immunity [18]. Vitamin D also regulates the normal development and function of the natural killer cells that produce high amounts of cytokines IL-4 and IFN- $\gamma$ [19]. It has also been observed that the production of IL-1 $\beta$ and IL- 8 is increased both in neutrophils and macrophages and that the phagocytic and bactericidal effects of macrophages were increased [18] [19]. On the other hand, vitamin inhibits the maturation, differentiation and survival of dendritic cells, thereby reducing the antigen presentation capacity and activation of $\mathrm{T}$ cells and contributing to a tolerogenic state [20]. Not only the innate immune system, but also adaptive immunity has been suggested to be affected by vitamin D. For instance, vitamin D modulates the differentiation and activation of CD $4^{+}$lymphocytes via binding to VDRs on T cells [21]. However, at the same time, it inhibits the production of proinflammatory cytokines, including IL-2, IL-17, and IFN- $\gamma$ [22]. Vitamin D has also been mentioned as suppressing the proliferation and immunoglobulin production of B cells and their differentiation to plasma cells [23].

Since the urinary system is of particular importance to possible pregnancy complications, the researchers have suggested that vitamin $\mathrm{D}$ supports and en- 
hances innate or acquired protective reactions, such as antimicrobial peptides (AMP), which are synthesized by immune and epithelial cells, bind foreign microbes, and neutralize them in the urinary system [24] [25]. It has been indicated that vitamin D stimulates the production of cathelicidin, which is the most important AMP in certain populations, including children, pregnant women, postmenopausal women, elderly people, and renal transplant patients [18] [26] [27] [28]. Although the effects of vitamin D and its probable mechanisms have been investigated for UTIs during pregnancy, there has, as yet, been no study regarding the association between maternal vitamin D and ASB, which is also a crucial parameter in early pregnancy screening and is related to several perinatal complications, including preterm labor, GDM, preeclampsia, and SGA. Therefore, the present study aimed to determine whether there was an association between maternal blood vitamin D levels and ASB in early pregnancy. Despite no significant relationship being found, with respect to the previous studies concerning vitamin D status and UTIs, the authors postulate that maternal vitamin D levels could significantly affect both innate and adaptive immunity and influence the presence of ASB in early pregnancy.

\section{Conclusion}

In conclusion, maintaining adequate vitamin $\mathrm{D}$ levels is one of the most important fundamentals of antenatal care. Therefore, vitamin D must be supplemented for women with vitamin D insufficiency or deficiency during pregnancy [29]. In this study, different from our initial assumption, vitamin D and presence of ASB were not related to each other. Further study is needed to confirm this result on a larger sample size. Putting this result aside, adequate vitamin D level and detection/protection/treatment of ASB during pregnancy are important.

\section{Conflicts of Interest}

The authors declare no conflicts of interest regarding the publication of this paper.

\section{References}

[1] García, J.I., Sepúlveda, S. and Noriega-Hoces, L. (2010) Beneficial Effect of Reduced Oxygen Concentration with Transfer of Blastocysts in IVF Patients Older than 40 Years Old. Health, 2, 1010-1017. https://doi.org/10.4236/health.2010.29149

[2] Kaszyńska, M. and Wieliczko, M. (2019) Asymptomatic Bacteriuria in Pregnancy. Wiadomości Lekarskie, 72, 2232-2234. https://doi.org/10.36740/WLek201911208

[3] Nicolle, L.E., Gupta, K., Bradley, S.F., et al. (2019) Clinical Practice Guideline for the Management of Asymptomatic Bacteriuria: 2019 Update by the Infectious Diseases Society of America. Clinical Infectious Diseases, 68, 1611-1615. https://doi.org/10.1093/cid/ciz021

[4] Dutra, L.V., Affonso-Kaufman, F.A., Cafeo, F.R., et al. (2020) Association between Vitamin D Plasma Concentrations and VDR Gene Variants and the Risk of Premature Birth. BMC Pregnancy and Childbirth, 20, Article No. 3. https://doi.org/10.1186/s12884-019-2671-2 
[5] Arnljots, R., Snaebjörnsson Arnljots, E., Thorn, J., et al. (2019) Bacteriuria and Vitamin D Deficiency: A Cross Sectional Study of 385 Nursing Home Residents. BMC Geriatrics, 19, Article No. 381. https://doi.org/10.1186/s12877-019-1400-Z

[6] Lacroix, M., Battista, M.C., Doyon, M., et al. (2014) Lower Vitamin D Levels at First Trimester Are Associated with Higher Risk of Developing Gestational Diabetes Mellitus. Acta Diabetologica, 51, 609-616.

https://doi.org/10.1007/s00592-014-0564-4

[7] De-Regil, L.M., Palacios, C., Lombardo, L.K., et al. (2016) Vitamin D Supplementation for Women during Pregnancy. Cochrane Database of Systematic Reviews, 14, CD008873. https://doi.org/10.1002/14651858.CD008873.pub3

[8] Roth, D.E., Leung, M., Mesfin, E., et al. (2017) Vitamin D Supplementation during Pregnancy: State of the Evidence from a Systematic Review of Randomised Trials. BMJ, 359, j5237. https://doi.org/10.1136/bmj.j5237

[9] Marshall, I., Mehta, R., Ayers, C., et al. (2016) Prevalence and Risk Factors for Vitamin D Insufficiency and Deficiency at Birth and Associated Outcome. BMC Pediatrics, 16, Article No. 208. https://doi.org/10.1186/s12887-016-0741-4

[10] Josefson, J.L., Reisetter, A., Scholtens, D.M., et al. (2016) Maternal BMI Associations with Maternal and Cord Blood Vitamin D Levels in a North American Subset of Hyperglycemia and Adverse Pregnancy Outcome (HAPO) Study Participants. PLoS One, 11, e0150221. https://doi.org/10.1371/journal.pone.0150221

[11] Zhou, J., Su, L., Liu, M., et al. (2014) Associations between 25-Hydroxyvitamin D Levels and Pregnancy Outcomes: A Prospective Observational Study in Southern China. European Journal of Clinical Nutrition, 68, 925-930.

https://doi.org/10.1038/ejen.2014.99

[12] Pfotenhauer, K.M. and Shubrook, J.H. (2017) Vitamin D Deficiency, Its Role in Health and Disease, and Current Supplementation Recommendations. The Journal of the American Osteopathic Association, 117, 301-305.

[13] Koivisto, O., Hanel, A. and Carlberg, C. (2020) Key Vitamin D Target Genes with Functions in the Immune System. Nutrients, 12, E1140.

https://doi.org/10.3390/nu12041140

[14] Bialy, L., Fenton, T., Shulhan-Kilroy, J., et al. (2020) Vitamin D Supplementation to İmprove Pregnancy and Perinatal Outcomes: An Overview of 42 Systematic Reviews. BMJ Open, 10, e032626. https://doi.org/10.1136/bmjopen-2019-032626

[15] Osman, O.M., Gaafar, T., Eissa, T.S., et al. (2020) Prevalence of Vitamin D Deficiency in Egyptian Patients with Pregnancy-Induced Hypertension. Journal of Perinatal Medicine, 48, 583-588. https://doi.org/10.1515/jpm-2020-0055

[16] Haghdoost, S., Pazandeh, F., Darvish, S., et al. (2019) Association of Serum Vitamin D Levels and Urinary Tract Infection in Pregnant Women: A Case Control Study. European Journal of Obstetrics \& Gynecology and Reproductive Biology, 243, 51-56. https://doi.org/10.1016/j.ejogrb.2019.10.015

[17] Mohammadzadeh, I., Darvish, S., Qujeq, D., et al. (2020) Association of Serum 25-OH Vitamin $\mathrm{D}_{3}$ with Serum IgE and the Pediatric Asthma Severity Score in Patients with Pediatric Asthma. Allergy \& Asthma Proceedings, 41, 126-133. https://doi.org/10.2500/aap.2020.41.190025

[18] Heidari, B., Hajian-Tilaki, K. and Babaei, M. (2019) Vitamin D Deficiency and Rheumatoid Arthritis: Epidemiological, Immunological, Clinical and Therapeutic Aspects. Mediterranean Journal of Rheumatology, 30, 94-102.

[19] Övünç Hacıhamdioğlu, D., Altun, D., Hacıhamdioğlu, B., et al. (2016) The Association between Serum 25-Hydroxy Vitamin D Level and Urine Cathelicidin in Child- 
ren with a Urinary Tract Infection. Journal of Clinical Research in Pediatric Endocrinology, 8, 325-329. https://doi.org/10.4274/jcrpe.2563

[20] Vanherwegen, A.S., Cook, D.P., Ferreira, G.B., et al. (2019) Vitamin D-Modulated Dendritic Cells Delay Lethal Graft-versus-Host Disease through Induction of Regulatory T Cells. The Journal of Steroid Biochemistry and Molecular Biology, 188, 103-110. https://doi.org/10.1016/j.jsbmb.2018.12.013

[21] Ding, Y., Liao, W., He, X.J., et al. (2017) Effects of $1,25(\mathrm{OH})_{2} \mathrm{D}_{3}$ and Vitamin D Receptor on Peripheral $\mathrm{CD}^{+} / \mathrm{CD}^{+}$Double-Positive T Lymphocytes in a Mouse Model of Systemic Lupus Erythematosus. Journal of Cellular and Molecular Medicine, 21, 975-985. https://doi.org/10.1111/jcmm.13037

[22] Krivoy, A., Satz, J., Hornfeld, S.H., et al. (2020) Low Levels of Serum Vitamin D in Clozapine-Treated Schizophrenia Patients Are Associated with High Levels of the Proinflammatory Cytokine IL-6. International Clinical Psychopharmacology, 35, 208-213. https://doi.org/10.1097/YIC.0000000000000303

[23] Rolf, L., Muris, A.H., Hupperts, R., et al. (2014) Vitamin D Effects on B Cell Function in Autoimmunity. Annals of the New York Academy of Sciences, 1317, 84-91. https://doi.org/10.1111/nyas.12440

[24] Chen, L., Eapen, M.S. and Zosky, G.R. (2017) Vitamin D Both Facilitates and Attenuates the Cellular Response to Lipopolysaccharide. Scientific Reports, 7, Article No. 45172. https://doi.org/10.1038/srep45172

[25] Nouari, W., Ysmail-Dahlouk, L. and Aribi, M. (2016) Vitamin D3 Enhances Bactericidal Activity of Macrophage against Pseudomonas aeruginosa. International Immunopharmacology, 30, 94-101. https://doi.org/10.1016/j.intimp.2015.11.033

[26] Kwon, Y.E., Kim, H., Oh, H.J., et al. (2015) Vitamin D Deficiency Is an Independent Risk Factor for Urinary Tract Infections after Renal Transplants. Medicine (Baltimore), 94, e594. https://doi.org/10.1097/MD.0000000000000594

[27] Ramos, N.L., Sekikubo, M., Kironde, F., et al. (2015) The Impact of Vitamin D on the Innate Immune Response to Uropathogenic Escherichia coli during Pregnancy. Clinical Microbiology and Infection, 21, 482.e1-482.e7. https://doi.org/10.1016/j.cmi.2014.12.010

[28] Oberg, J., Verelst, M., Jorde, R., et al. (2017) High Dose Vitamin D May Improve Lower Urinary Tract Symptoms in Postmenopausal Women. The Journal of Steroid Biochemistry and Molecular Biology, 173, 28-32. https://doi.org/10.1016/j.jsbmb.2017.03.013

[29] Owens, N.J. (2020) Vitamin D Supplementation for Women during Pregnancy: Summary of a Cochrane Review. Explore (NY), 16, 73-74.

https://doi.org/10.1016/j.explore.2019.10.002 